\title{
Wetting and drying performance of cross-laminated timber related to on-site moisture protections: Field measurements and hygrothermal simulations
}

\author{
Lin Wang, ${ }^{1, *}$, Jieying Wang ${ }^{2}$, and Hua $\mathrm{Ge}^{1}$ \\ ${ }^{1}$ Concordia University, Department of Building, Civil and Environmental Engineering, 1455 Boulevard de Maisonneuve O. Montreal, \\ QC H3G 1M8, Canada \\ ${ }^{2}$ FPInnovations, 2665 East Mall Vancouver, BC V6T 1Z4, Canada
}

\begin{abstract}
Cross-laminated timber (CLT) panels are increasingly used in mid-rise buildings or even taller structures in North America. However, prolonged exposure to moisture during construction and in service is a durability concern for most wood products including CLT. To investigate practical solutions for reducing on-site wetting of mass timber construction, CLT specimens with a range of moisture protection measures, in six groups were tested in the backyard of FPInnovations' Vancouver laboratory from Oct. 2017 to Jan. 2018. This study investigates the wetting and drying behaviours of the tested CLT specimens through 2-D hygrothermal simulations. The simulations are performed for base specimens (no protection measures) of group 1 (without joint or plywood spline) and group 2 (with a butt joint and plywood spline). For group 1, three data sources of material properties are used to create the models, and the data that led to the best agreement between simulations and measurement are used for creating the models of group 2. For group 2, two types of hygrothermal models are created with or without considering the differences in water absorption between the transverse and the longitudinal grain orientations. In addition, rain penetration is taken into account for the joint area. It is found that the model with considering the differences between transverse and longitudinal grain orientations shows a better agreement than that without considering such differences.
\end{abstract}

\section{Introduction}

Cross-laminated timber (CLT) panels are increasingly used to build mid-rise buildings or even taller structures in North America due to their good structural and fire safety performance, carbon storage capacity, light weight, and prefabricated nature [1, 2]. However, prolonged exposure to moisture during construction and in service is a durability concern for most wood products including CLT. The chance is high in most climates for the timber to be exposed to moisture sources, typically rain during transportation or construction before a permanent moisture barrier is applied. The built-in moisture may result in serious durability related problems if it is not removed before the CLT panels are enclosed by other building envelope materials.

The wetting and drying behaviours of CLT panels and CLT wall assemblies have been investigated through laboratory test, field measurement and hygrothermal simulations [3-6]. Most of the previous studies, particularly hygrothermal modelling assumed homogeneous and isotropic material properties for entire CLT panel when assessing its moisture responses to environmental variations. However, as a glued solid wood product, CLT's anisotropic properties both inherent to wood and resulting from the manufacturing method are always important and should be taken into account. For example, wood typically has very different water absorption properties between the transverse direction and longitudinal grain orientation [7]. Such difference may result in significant differences in moisture response at different locations, depending on whether an end grain or a flat grain surface is exposed to wetting, and thereby influence the performance of an entire wall assembly.

To investigate practical solutions for on-site moisture management of mass timber construction, CLT specimens with different moisture protection measures were tested in the backyard of FPInnovations' Vancouver laboratory from Oct. 2017 to Jan. 2018 [8]. The tested panels were divided into six groups with different setup reflecting different application scenarios, water protection measures, and environmental conditions. Moisture sensors were installed at different layers of each CLT specimen to monitor the moisture response in transverse and longitudinal directions, respectively. This paper investigates the wetting and drying behaviours of two types of base specimens, without any moisture protection measures, through hygrothermal simulation. The 2-D hygrothermal models of the selected CLT specimens are created using a

* Corresponding author: forestwang2013@gmail.com 
well-known hygrothermal simulation program DELPHIN, with considering different material properties for transverse and longitudinal directions. The models are calibrated by comparing the simulation results with the field measurements so that the calibrated models can be used as the basis to develop models for other specimens under various wetting and drying environmental conditions.

\section{Methods}

\subsection{Experimental description}

In the test conducted by FPInnovations, thirty 3-ply CLT specimens, measuring 400x400x87 mm, were collected from trimmings from factory production and tested for wetting and drying behaviour over three months. The CLT was made with visually graded Spruce-Pine-Fir (SPF) lumber and bonded with polyurethane adhesive. The specimens were exposed to the rainy wintertime weather or placed in a shed to simulate different wetting and drying scenarios.

The specimens that are selected for hygrothermal modelling are the base samples from group 1 and group 2 without any water protection measures. The specimen from group 1 is in horizontal setup with the top wide surface exposed to weather, without any joint. Moisture sensors were installed at two depths, $6 \mathrm{~mm}$ and $12 \mathrm{~mm}$ below the top exposed surface. The specimen from group 2 is also in horizontal setup but includes a butt joint with plywood spline connecting two pieces of CLT. Two pairs of moisture sensors were installed in the middle lamina of the CLT to detect moisture changes in the longitudinal direction: one pair $12 \mathrm{~mm}$ and the other pair $25 \mathrm{~mm}$ away from the end grain at the joint; a third pair of sensors was installed in the top layer, about 25 $\mathrm{mm}$ away from the edge but in the transverse direction. Two additional pairs of sensors were installed in the plywood spline to monitor the moisture changes in its top and bottom surface, respectively. Each pair of moisture sensors was coated except the tip which was expected to measure the MC at the target depth. The MC sensors were calibrated for Douglas fir at temperature of $21{ }^{\circ} \mathrm{C}$, and the accuracy is expected to be within $\pm 2 \%$. Moisture content measurements above fiber saturation i.e. typically over $30 \%$, are considered as indicative rather than accurate. Fig. 1 shows the configurations and sensor locations of the CLT specimens.

\subsection{Hygrothermal model setup}

\subsubsection{Material properties}

Material properties of CLT panel tested from different laboratories or studies have large variations. This paper investigates the impact of such variations in hygric properties on simulation results. The material properties of the CLT panel from three data sources- Alsayegh et al., 2013; Kumaran, 2002 (ASHRAE RP 1018); McClung, 2013 [9-11], are applied to simulation.
For the data from Alsayegh et al. [9], the material properties of Western Spruce-Pine-Fir (WSPF) are used in simulations. The sorption isotherm of WSPF included the $\mathrm{RH}$ range from $50 \%$ to $95 \%$ only, the sorption isotherm corresponding to $\mathrm{RH}$ above $95 \%$ is determined based on the sorption tests of red pine at high RH levels by Wang et al. [12]. The material properties from ASHRAE RP 1018 [10] is based on the properties of spruce. In that report, the equilibrium moisture content (EMC) at total saturation condition is $221 \%$, while the EMC at RH $99.78 \%$ in the desorption data set is $187 \%$, and it was noted that the EMC at higher RH level is obtained by pressure plate method. In this paper, the EMC $187 \%$ is selected as the saturation water content for hygrothermal simulation since the total saturation condition is not realistic. The moisture storage function from McClung [11] was adapted from the spruce properties in WUFI database based on WSPF without detailed test information. The A-value was determined based on the laboratory test by Lepage (2012) [13]. The hygric properties of CLT from three data sources are summarized and listed in Table 1. The A-values, i.e. water absorption coefficient, based on ISO test [14] from these data sources are all provided, without differentiating transverse direction and longitudinal direction. According to Glass and Zelinka [7], the water absorption coefficients for softwoods are in the range 10 $\mathrm{g} / \mathrm{m}^{2} \mathrm{~s}^{0.5}-16 \mathrm{~g} / \mathrm{m}^{2} \mathrm{~s}^{0.5}$ in the longitudinal direction and 1 $\mathrm{g} / \mathrm{m}^{2} \mathrm{~s}^{0.5}-7 \mathrm{~g} / \mathrm{m}^{2} \mathrm{~s}^{0.5}$ in the transverse direction. Based on the laboratory test of 15 structural composite lumber by Wang (2018), the water absorption coefficient in longitudinal direction could be 10 times higher than transverse direction [15]. Therefore, for group 2 with plywood spline, the A-value is set as $12 \mathrm{~g} / \mathrm{m}^{2} \mathrm{~s}^{0.5}$ for the longitudinal direction, which is the same as that suggested by McClung [11] and in the range suggested by Glass and Zelinka [8].

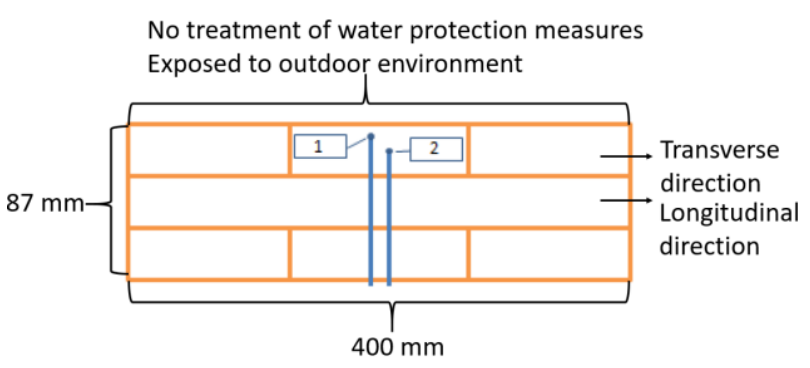

a) Group 1

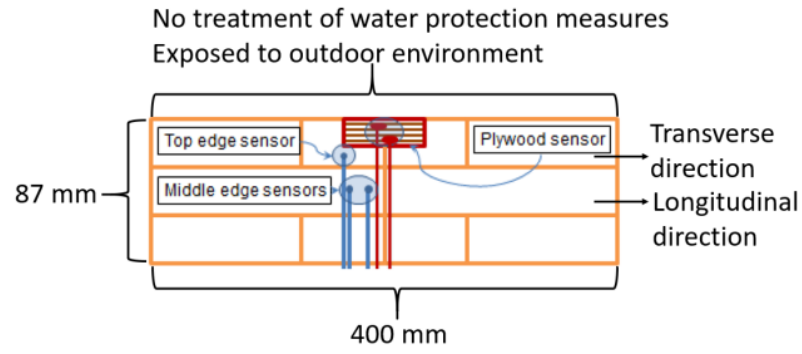

b) Group 2

Fig. 1 Configuration and sensor locations of the CLT panels (adapted from reference [8]). 
For the transverse direction, it is assumed as $2 \mathrm{~g} / \mathrm{m}^{2} \mathrm{~s}^{0.5}$. The moisture diffusivity is calculated based on the following equation [16]

$$
D_{w s}=3.8 \cdot\left(\frac{A}{W_{f}}\right)^{2} 1000^{\left(\frac{W}{W_{f}}-1\right)}
$$

Where $\mathrm{D}_{\mathrm{ws}}-$ moisture diffusivity for suction at certain moisture content level $\left(\mathrm{m}^{2} / \mathrm{s}\right) ; \mathrm{A}$ - water absorption coefficient $\left(\mathrm{kg} / \mathrm{m}^{2} \mathrm{~s}^{0.5}\right) ; \mathrm{w}_{\mathrm{f}}-$ saturation moisture content $\left(\mathrm{kg} / \mathrm{m}^{3}\right) ; \mathrm{w}-$ moisture content $\left(\mathrm{kg} / \mathrm{m}^{3}\right)$.

Table 1. Hygric material properties from three data sources

\begin{tabular}{|l|l|l|l|}
\hline & $\begin{array}{l}\mathbf{W}_{\mathbf{f}} \\
\left(\mathbf{k g} / \mathbf{m}^{\mathbf{3}}\right)\end{array}$ & $\begin{array}{l}\boldsymbol{\mu}_{\text {Dry }} \\
-\end{array}$ & $\begin{array}{l}\mathbf{A} \\
\left(\mathbf{k g} / \mathbf{m}^{\mathbf{2}} \mathbf{s}^{\mathbf{0 . 5}}\right)\end{array}$ \\
\hline $\begin{array}{l}\text { Alsayegh et al., } \\
2013\end{array}$ & 168 & 1490 & 0.00195 \\
\hline ASHRAE RP 1018 & 748 & 499 & 0.002 \\
\hline McClung, 2013 & 573 & 1876 & 0.012 \\
\hline
\end{tabular}

Saturation water content can be defined as the EMC corresponding to RH $100 \%$ [16]. However, it is difficult to precisely control a stable $\mathrm{RH}$ at high resolution when it gets close to $100 \%$, therefore, pressure plate method is often used to measure the EMC at high RH levels. According to the lab test of red pine conducted by Wang et al. [12], the moisture content is about $30 \%$ to $40 \%$ when the $\mathrm{RH}$ is getting close to $100 \%$. The moisture content decreases from $170 \%$ to $40 \%$ with the variation of suction pressure from 2 to 50 bar, but at a constant RH (100\%). The saturation water content from Alsayegh represents the moisture content corresponding to a high suction pressure but also $100 \% \mathrm{RH}$. On the other hand, the saturation water content from ASHRAE RP 1018 and McClung represent the moisture content corresponding to a low suction pressure, which is close to the vacuum saturation of pressure plate test.

For a piece of dried wood used in construction, how much moisture can actually get into the wood largely depends on the wood species, size of the wood, and the exterior pressure. Most softwood species grown in cold climates typically are quite difficult for water to penetrate, particularly in transverse direction even under pressure, once dried. Assuming that all pores inside wood would be saturated with water is not realistic for most applications. Therefore, the EMC measured at vacuum saturation is very rare under real situations.

The hygric property curves including moisture storage function, vapor resistance factor as a function of relative humidity and moisture diffusivity as a function of normalized moisture content are presented in Fig. 2.

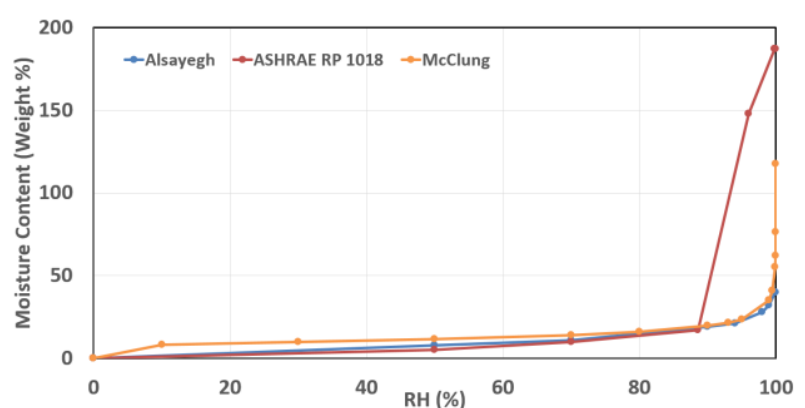

a) Moisture storage function

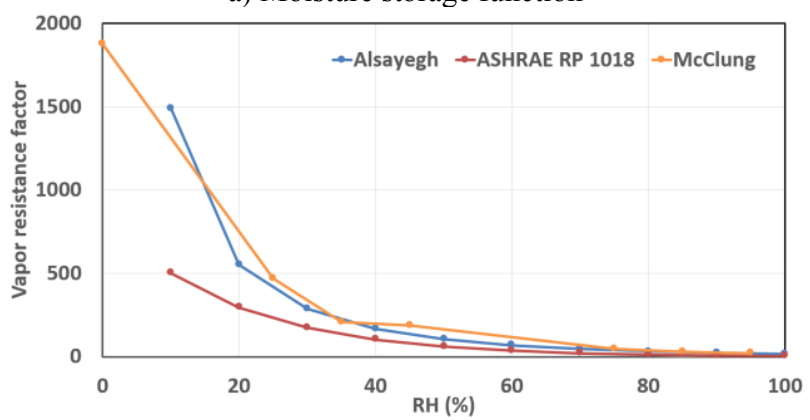

b) Vapor resistance factor as a function of relative humidity

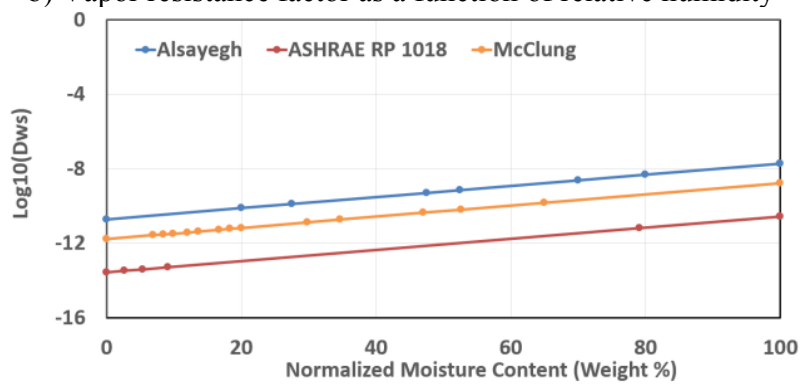

c) Moisture diffusivity as a function of normalized moisture content

Fig. 2. Hygric material property curves from 3 data sources.

\subsubsection{Boundary conditions}

The boundary conditions include heat transfer coefficient, vapor transfer coefficient and rain exposure and deposition factors. The solar radiation is not considered in the simulation, therefore solar absorptivity is excluded from the modelling. The boundary conditions are assigned to the top surface of the CLT samples, as listed in Table 2.

Table 2. Boundary conditions

\begin{tabular}{|l|l|l|l|}
\hline $\begin{array}{l}\boldsymbol{\alpha}_{\text {ex }} \\
\left(\mathbf{W} / \mathbf{m}^{\mathbf{2}} \cdot \mathbf{K}\right)\end{array}$ & $\begin{array}{l}\boldsymbol{\beta}_{\text {ex }} \\
(\mathbf{s} / \mathbf{m})\end{array}$ & $\begin{array}{l}\mathbf{F}_{\mathbf{E}} \\
-\end{array}$ & $\begin{array}{l}\mathbf{F}_{\mathbf{D}} \\
-\end{array}$ \\
\hline 17 & $1 \mathrm{E}-8$ & 1.0 & 1.0 \\
\hline
\end{tabular}

$\alpha^{\mathrm{ex}} \quad$ heat transfer coefficient of the surface

$\beta^{\text {ex }}$ - vapor transfer coefficient of the surface

$\mathrm{F}_{\mathrm{E}}$ - rain exposure coefficient

$\mathrm{F}_{\mathrm{D}}$ - rain deposition coefficient 


\subsubsection{Climate conditions}

The climatic conditions used in the simulation include temperature, relative humidity and horizontal rainfall intensity. The temperature and relative humidity are from Vancouver International Airport weather data provided by Environmental Canada. The horizontal rainfall intensity was measured in the backyard of FPInnovations. There is only daily rain data in the weather data file, so the cumulative daily precipitation is divided by 24 to get the hourly rain data. The horizontal rainfall intensity is presented in Fig. 3.

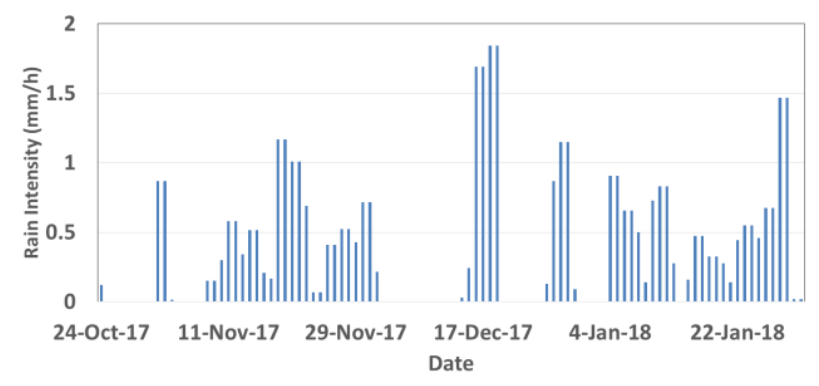

Fig. 3. Measured horizontal rainfall intensity.

\subsubsection{Rain leakage}

For group 2, a plywood spline is used to connect two pieces of CLT panels. The plywood spline was fastened by screws, therefore, there were gaps between the spline perimeter and the CLT, and also between the two CLT pieces, which may result in exacerbated rain penetration into the plywood and also into the two CLT pieces through their exposed edges with end grain.

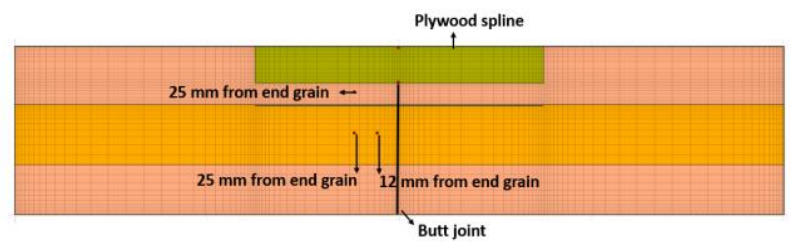

a) locations of the sensors and end grain

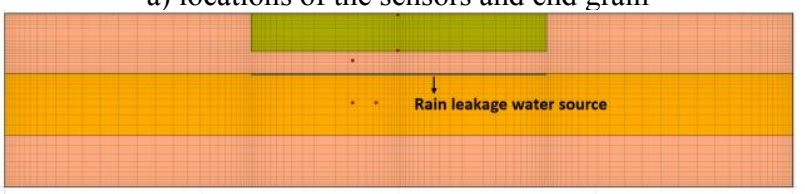

b) rain leakage path 1

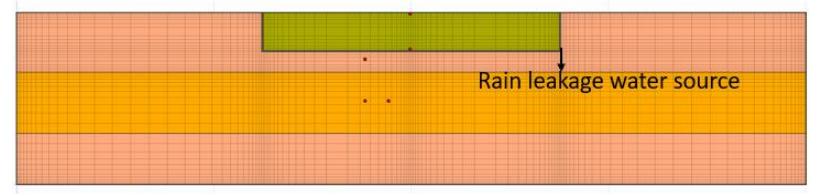

c) rain leakage path 2

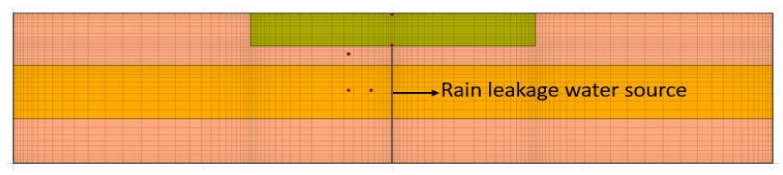

d) rain leakage path 3

Fig. 4. Location of the water source for simulating rain leakage.
To simulate the rain penetration, a water source that represents $1 \%$ of the horizontal rain is added in the boundary between transverse direction and longitudinal direction (rain leakage path 1 shown in Fig. 4b), the perimeter around the plywood spline (rain leakage path 2 shown in Fig. 4c) and the butt joint between two CLT pieces (rain leakage path 3 shown in Fig. 4d). For group 1 , there is only one piece of CLT panel with the transverse section and longitudinal section being glued together, which has less chance for rainwater penetrating to into the CLT panel. Although the rainwater fell on the top surface of the CLT panels might be drained from the edges of the panel, the impact of the run off water is much less than those penetrated into the panel. Therefore, in this study, only penetrated rain water is taken into account.

\section{Results and discussion}

\subsection{Simulation results for group 1}

Fig. 5 shows that simulation results with the properties based on Alsayegh's study have the best agreement with the measurements. For the results using material properties from ASHRAE RP 1018 and McClung, the moisture contents simulated are excessively higher than the measurements.

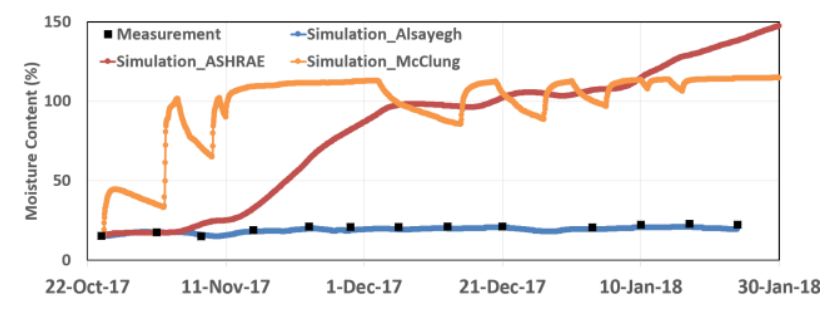

a) $6 \mathrm{~mm}$ from top surface

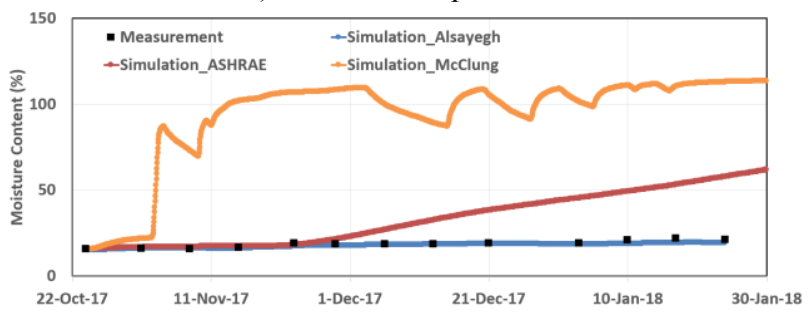

b) $12 \mathrm{~mm}$ from top surface

Fig. 5. Comparison between simulation results and measurements for group 1.

This is because the saturation water content from ASHRAE RP 1018 and McClung are much higher than that from Alsayegh, as shown in Table 1. The moisture diffusivity from McClung is much higher than that from ASHRAE, therefore the simulation result from McClung has the highest moisture content. For the simulation with Alsayegh's data, the discrepancy between simulation results and measurements may be caused by the estimated rain data. The exclusion of solar radiation may also impact the accuracy of the simulation results. The discrepancy between simulation and measurement 
is less at the $12 \mathrm{~mm}$ location (RMSE 1.4) than that at 6 mm location (RMSE 4.2) because the moisture content at deeper location is more stabilized than that at the upper location. Locations closer to end grain are more susceptible to water penetration. Since the model with Alsayegh's data has the best accuracy for group 1, the Alsayegh's data is used for simulating the base specimen of group 2.

\subsection{Simulation results for group 2}

To investigate the effect of A-value in transverse and longitudinal direction, simulations are performed for two models: 1) A-value $\left(0.00195 \mathrm{~kg} / \mathrm{m}^{2} \mathrm{~s}^{0.5}\right)$ is assigned to the entire CLT panel; 2) The A-value used for longitudinal direction is increased to $0.012 \mathrm{~kg} / \mathrm{m}^{2} \mathrm{~s}^{0.5}$, which is the same as the value suggested by McClung [11] and in the range that is suggested by Glass and Zelinka [7]. The A-value for transverse direction is kept as the original value. Fig. 6 shows the scatter plot of comparison between these two models for three locations of the base specimen in group 2 under the first rain leakage path. The measured MCs are recorded once every week, while the simulated MCs are plotted for every hour.

For the middle layer, the simulation results from model 2, which uses different A-values for transvers and longitudinal directions have better agreement with measurement than model 1, which uses a lower A-value for the entire CLT panel. Model 2 underestimates the wetting rate from October 2017 to November 2017, and the underestimation is more significant for $12 \mathrm{~mm}$ location than for the $25 \mathrm{~mm}$ location. The simulation results are getting closer to measurements after December when the moisture content level was stable at around $30 \%$. However, there is a significant drying in the period between the end of December 2017 and the beginning of January 2018 as indicated by the measurement, but the simulation results do not reflect this drying because DELPHIN does not consider the difference in moisture diffusivity between suction and redistribution. The simulation results from model 1 are significantly lower than the measurements in both wetting rate and moisture content level, because this model does not consider the A-value difference between transverse and longitudinal directions.

For the top layer, the results from model 1 and model 2 are almost the same and both models are able to capture the trend of the measurement. The top layer is in transverse direction, which A-value is much less than that in longitudinal direction, therefore, there is no significant difference between model 1 and model 2 .

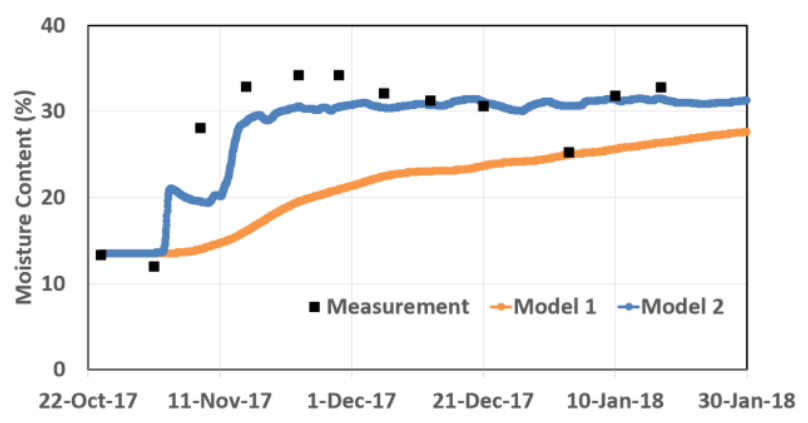

a) Middle layer $12 \mathrm{~mm}$ from the end grain
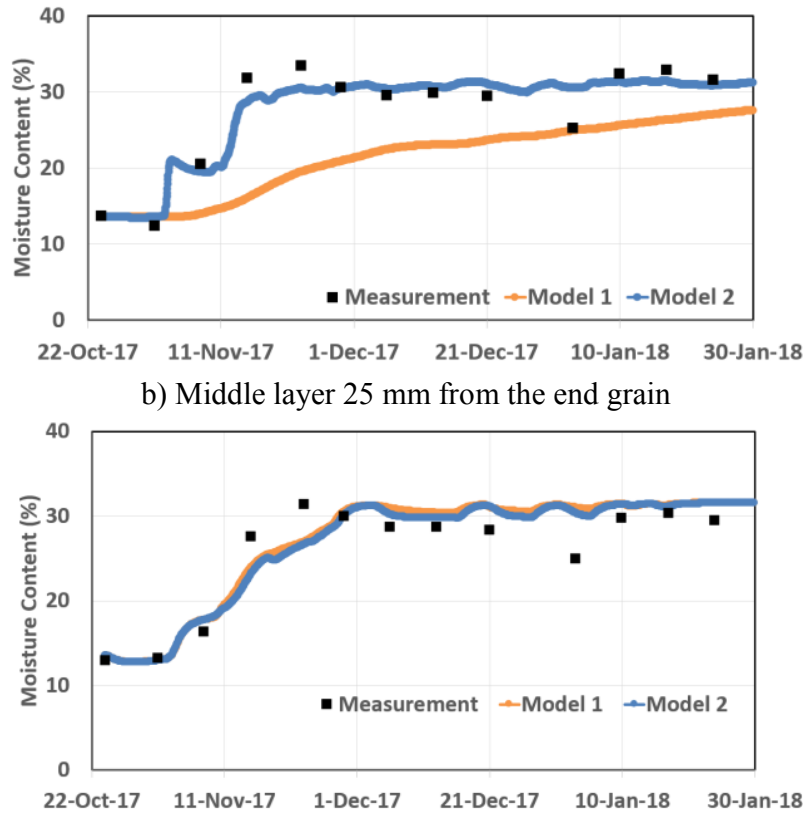

c) Top layer $25 \mathrm{~mm}$ from the end grain

Fig. 6. Comparison between simulation and measurement for group 2 (rain leakage path 1).

\subsection{Comparison among different rain leakage paths}

The impact of the rain leakage path is investigated based on model 2, which is using separate A-value for transverse and longitudinal direction and has a better agreement with measurement than model 1. Fig. 7 shows the simulated moisture contents for three rain leakage paths at three locations.

For the moisture content in middle layer, the models with rain leakage path 1 (water source at the boundary between transverse section and longitudinal section) and path 3 (water source at the butt joint of the CLT panels) have similar moisture content level, while the simulated moisture content in path 3 has more signficant variation than that in path 1 . The model with rain leakage path 2 (water source in the perimeter of plywood spline) cannot capture the trend of moisture content variation in the middle layer.

For the moisture content in top layer, all of the three rain leakge scenarios have similar trend with the measured mositure content, while the result from rain leakage path 2 has the best agreement with the measurement. 


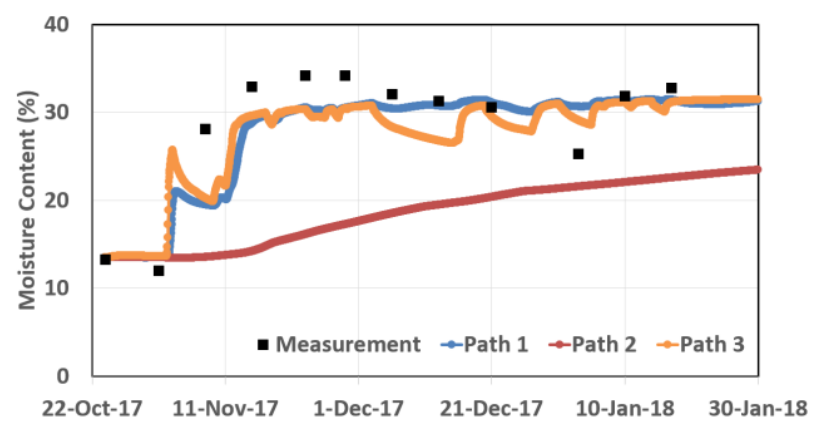

a) Middle layer $12 \mathrm{~mm}$ from the end grain

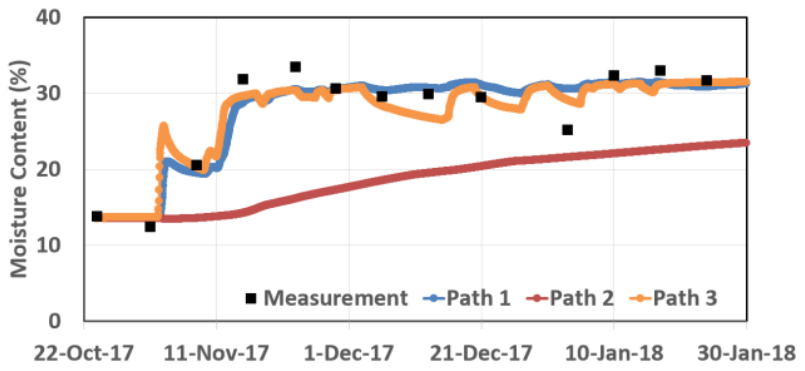

b) Middle layer $25 \mathrm{~mm}$ from the end grain

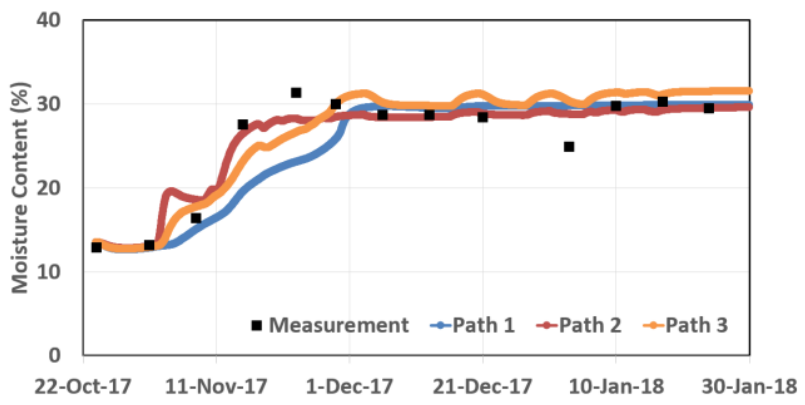

c) Top layer $25 \mathrm{~mm}$ from end grain

Fig. 7. Comparison among different rain leakage paths.

\section{Conclusion}

This paper presents the hygrothermal modelling of two types of CLT panels that are tested under natural weather conditions in Vancouver. The models are created using three data sources of material properties for group 1 without plywood spline and the A-value difference between transvers and longitudinal is taken into account for group 2 with plywood spline. Based on the comparison between the simulation results and measurements, it is found that the simulation results with a saturation water content of around $40 \%$ has the best agreement with measurements. For group 2 with plywood spline, the model that has considered A-value difference between transverse and longitudinal directions has better agreement with measurement than that without this consideration. In addition, simulation results with rain leakage path 3 , which assumes the water source at the gap between two pieces of CLT panels, have the best agreement with the measurements. The validated models for group 1 and group 2 can be used as the basis to develop the hygrothermal models for other groups with different water protection measures.

\section{References}

1. S. Gagnon, C. Pirvu, CLT Handbook: Crosslaminated Timber, (FPInnovations Special Publication SP528-E. Canadian ed., FPInnovations, Quebec, 2011)

2. E. Karacabeyli, B. Douglas, Cross-laminated Timber (CLT) Hand Book, (FPInnovations Special Publication SP529-E. US ed., FPInnovations and Binational Softwood Lumber Council, Quebec, 2013)

3. V. Kukk, R. Horta, M. Pussa, G. Luciani, H. Kallakas, T. Kalamees, J. Kers, Impact of cracks to the hygrothermal properties of CLT water vapour resistance and air permeabillity, 11th Nordic Symposium on Building Physics (2017).

4. E. L. Schmidt, M. Riggio, A. R. Barbosa, I. Mugabo, Environmental response of a CLT floor panel : lessons for moisture management and monitoring of mass timber buildings, Build. Environ. 148, 609-622 (2019).

5. R. McClung, H. Ge, J. Straube, J. Wang, Hygrothermal performance of crosslaminated timber wall assemblies with built-in moisture: field measurements and simulations, Build. Environ. 71, 95-110 (2014).

6. L. Wang, H. Ge, Hygrothermal performance of cross-laminated timber wall assemblies : a stochastic approach, Build. Environ. 97, 11-25 (2016)

7. S. V. Glass, S. L. Zelinka, Moisture relations and physical properties of wood, Wood handboodwood as an engineering material (United State Department of Agriculture. Forest Products Laboratory. Centinnial Edition, 2010)

8. J. Wang, Wetting and drying performance related to on-site moisture protection of cross-laminated timber, technical report of FPInnovations (2018)

9. G.Alsayegh , P. Mukhopadhyaya,

J.Y. Wang, E. Zalok, D. Reenen. 2013. Preliminary characterization of physical properties of crosslaminated timber (CLT) panels for hygrothermal modelling. Advances in Civil Engineering Material, 2(1), 472-484 (2013)

10. M.K.Kumaran, J.C. Lackey, N. Normandin, F.Tariku, D.van Reenen, A thermal and moisture transport property database for common building and insulating materials. Final report from ASHRAE Research Project 1018-RP (2002)

11. R.McClung, Field study of hygrothermal performance of cross-laminated timber wall assemblies with built-in moisture. Master's thesis. Ryerson University, Ontario, Canada (2013)

12. J. Wang, P. Mukhopadhyaya, P.Morris, Sorption and capillary condensation in wood and the moisture content of red pine, J. Build. Phys., 37(4), 327-347 (2014) 
13. R. T. M. Lepage, Moisture response of wall assemblies of cross laminated timber construction in cold Canadian climates, Master's Thesis, University of Waterloo, Ontario, Canada (2012).

14. International Standard Organization, Standard 15148 : Hygrothermal performance of building materials and pruducts-determination for water absorption coefficient by partial immersion, ISO, Geneva, Switzerland (2002)

15. J. Wang, Preliminary assessment of moisturerelated properties for structural composite lumber, technical report from FPInnovations (2018)

16. Fraunhofer IBP, WUFI Pro 5.1 online help document (2009) 